\title{
Volumetric MRI Analysis of Brain Structures in Patients with History of First and Repeated Suicide Attempts: A Cross Sectional Study
}

\author{
Milda Sarkinaite ${ }^{1, *}$, Rymante Gleizniene ${ }^{1}\left(\mathbb{D}\right.$, Virginija Adomaitiene ${ }^{2}$, Kristina Dambrauskiene ${ }^{2}$, \\ Nijole Raskauskiene ${ }^{3}$ and Vesta Steibliene ${ }^{2,3}$ (D) \\ 1 Department of Radiology, Lithuanian University of Health Sciences, 44307 Kaunas, Lithuania; \\ rymante.gleizniene@lsmuni.lt \\ 2 Psychiatry Clinic of Lithuanian University of Health Sciences, 44307 Kaunas, Lithuania; \\ virginija.adomaitiene@lsmuni.lt (V.A.); kristina.dambrauskiene@lsmuni.lt (K.D.); \\ vesta.steibliene@lsmuni.lt (V.S.) \\ 3 Laboratory of Behavioural Medicine, Neuroscience Institute, Lithuanian University of Health Sciences, \\ 44307 Kaunas, Lithuania; nijole.raskauskiene@lsmuni.lt \\ * Correspondence: milda.sarkinaite@stud.lsmu.lt; Tel.: +370-67876580
}

check for updates

Citation: Sarkinaite, M.; Gleizniene, R.; Adomaitiene, V.; Dambrauskiene, K.; Raskauskiene, N.; Steibliene, V. Volumetric MRI Analysis of Brain Structures in Patients with History of First and Repeated Suicide Attempts: A Cross Sectional Study. Diagnostics 2021, 11, 488. https://doi.org/ 10.3390/diagnostics11030488

Academic Editor: Arvid Lundervold

Received: 11 February 2021

Accepted: 6 March 2021

Published: 10 March 2021

Publisher's Note: MDPI stays neutral with regard to jurisdictional claims in published maps and institutional affiliations.

Copyright: (c) 2021 by the authors. Licensee MDPI, Basel, Switzerland. This article is an open access article distributed under the terms and conditions of the Creative Commons Attribution (CC BY) license (https:/ / creativecommons.org/licenses/by/ $4.0 /)$.

\begin{abstract}
Structural brain changes are found in suicide attempters and in patients with mental disorders. It remains unclear whether the suicidal behaviors are related to atrophy of brain regions and how the morphology of specific brain areas is changing with each suicide attempt. The sample consisted of 56 patients hospitalized after first suicide attempt (first SA) $(n=29)$, more than one suicide attempt $(\mathrm{SA}>1)(n=27)$ and 54 healthy controls $(\mathrm{HC})$. Brain volume was measured using FreeSurfer 6.0 automatic segmentation technique. In comparison to HC, patients with first SA had significantly lower cortical thickness of the superior and rostral middle frontal areas, the inferior, middle and superior temporal areas of the left hemisphere and superior frontal area of the right hemisphere. In comparison to HC, patients after SA > 1 had a significantly lower cortical thickness in ten areas of frontal cortex of the left hemisphere and seven areas of the right hemisphere. The comparison of hippocampus volume showed a significantly lower mean volume of left and right parts in patients with SA $>1$, but not in patients with first SA. The atrophy of frontal, temporal cortex and hippocampus parts was significantly higher in repeated suicide attempters than in patients with first suicide attempt.
\end{abstract}

Keywords: suicide attempt; FreeSurfer; magnetic resonance imaging; hippocampus; frontal cortex; temporal cortex

\section{Introduction}

According to the World Health Organization, globally, 780,000 suicide occurrences are recorded each year (10.7 per 100,000 population), and there are from two to three times more suicide attempts [1]. In Lithuania, suicide is one of the major public health issues. It should be noted that Lithuania has been one of the countries with the highest suicide rate for more than 20 years [2]. With the rate of 31.9/10,000 Lithuania is in the first place in the European Union in terms of the number of suicides. It is three times higher compared to the rest of the world and twice as high as recorded in the EU (15.4 per 100,000 population) [1] Therefore, in Lithuania, as well as in the whole world, great importance is attached to identifying both psychosocial and neurobiological factors of suicidal behaviors for the purpose of effective suicide prevention.

A number of neurobiological models have been proposed to explain the suicidal behaviors [3]. The identification of these models could be the effective step in suicide prevention. Nowadays structural neuroimaging is one of the best modern methods for examinations of suicidal behaviors in the living brain [4]. There are more than 30 studies known which 
indicate that structural brain changes are found in suicide attempters, they also reveal how variation in brain volume is associated with pathogenesis of suicide [4]. However, data are quite contradictory; brain changes in most studies are more related to mental disorders than suicidal behaviors [4]. Atrophy of dorsolateral (DL) prefrontal cortex (PFC), ventrolateral (VL) areas of PFC and anterior cingulate cortex (ACC) is found in suicide attempters, the patients with depression or schizophrenia $[5,6]$. Other studies on suicidality detected grey matter atrophy in the left superior temporal gyrus, left orbitofrontal cortex (OFC), superior left parietal lobe, thalamus, insula of the right side, and some frontal regions [6-9]. In contrast, increased volumes of the right amygdala and the reciprocal inferior frontal white matter are also discovered in suicide attempters [6-9]. Research on suicidal behaviors in patients with unipolar disorder found support to volume reduction in right and left OFC, hippocampal volume in comparison to healthy controls [10].

To the best of our knowledge, there has been no investigation into brain volume changes after first and repeated SA. Thus, it is remains unclear, how the morphology of specific brain areas changes with each subsequent suicide attempt. In this cross-sectional study we examined structural differences in temporal cortex (TC), frontal cortex and hippocampal regions between patients with history of first and repeated SA in comparison to healthy controls by using brain magnetic resonance imaging (MRI) and automatic segmentation technique.

\section{Materials and Methods}

\subsection{Study Population and Settings}

Adults, non-psychotic patients, men and women, without cognitive impairment, any other organic brain disorder or severe unstable medical condition, admitted to Psychiatry department after SA during a six-month period, eligible for MRI scan were invited to participate in this cross-sectional study. All study patients completed a questionnaire that included assessment of sociodemographic characteristics, history of psychiatric treatment and hospitalization and history of suicide attempts.

Psychiatric diagnoses and suicide attempts were evaluated by a psychiatrist and defined under the Diagnostic and Statistical Manual of Mental Disorders 5th edition (DSM5) [11]. Depressive symptoms of the study patients were evaluated by psychiatrist using the structured interview guide for the Montgomery-Asberg Depression Rating Scale (MADRSSIGMA) (Copyright @2006 v.1, Janet B.W. Williams and Kenneth A. Kobak. All rights reserved.) [12]. This scale consisted of 10 questions and ratings were based on the patient's condition in the past week. Answers were rated in 7-point scale (0-no symptoms, 6-very extreme symptom severity); the sum of all ratings provided the severity of depressive symptoms. SA has been defined as a nonfatal self-directed, potentially injurious behavior with any intent to die as a result of the behavior [13]. The control group consisted of adult subjects (men and women), who consecutively came for preventive check-ups to a family physician at the Clinic of Family Medicine. The exclusion criteria for control group were the anamnesis of mental disorder, alcohol or drug abuse or dependence, anamnesis of SA, cognitive impairment, severe unstable medical conditions, any organic brain disorders. The study protocol and informed consent procedures were approved by the Bioethics Committee at the Lithuanian University of Health Sciences, Kaunas, Lithuania (2017-0623, No. BEC-LSMUCR-67). The investigation was carried out in accordance with the Declaration of Helsinki. Each study participant gave written informed consent prior to all study procedures.

Of all invited as study patients, 59 subjects (response rate $92 \%$ ) agreed to participate in the study. One patient was excluded due to specific MRI changes of carbon monoxide poisoning and 2 patients were excluded due to anamnesis of chronic alcohol consumption that could had caused brain changes. The healthy control (HC) group included 54 volunteers (response rate $68 \%$ ). Hence, the final study sample consisted of 56 study patients (mean age 40.8 (16.8) years, $35.2 \%$ of them were men) after SA and 54 HC (mean age 41.0 (16.3) years, $39.3 \%$ were men). There were no significant differences between patients and controls with 
regard to age and gender (Table 1). Of the 56 study patients included into final analysis, $21(37.5 \%)$ were diagnosed with major depressive disorder (MDD) (MADRS score 28.14 (7.9)); other - $26(46.43 \%)$ with adjustment disorder, $3(5.36 \%)$ with personality disorders and $6(10.71 \%)$ with anxiety disorders (MADRS score in this group was $9.34(1.69)$ ).

Table 1. Demographic characteristics of all study subjects.

\begin{tabular}{|c|c|c|c|c|c|c|}
\hline Characteristics & $\mathrm{HC}(n=54)$ & $\begin{array}{l}\text { All Patients after } \\
\text { SA }(n=56)\end{array}$ & $\mathrm{p}^{\mathrm{a}}$ & $\begin{array}{l}\text { First SA Group } \\
\quad(n=29)\end{array}$ & $\begin{array}{c}\text { SA }>1 \text { Group } \\
(n=27)\end{array}$ & $\begin{array}{c}\mathrm{F} / p \\
\text { Chi-Square }\end{array}$ \\
\hline $\begin{array}{l}\text { Age, mean (SD), } \\
\text { years range }\end{array}$ & $\begin{array}{c}41.0(16.3) \\
18-77\end{array}$ & $\begin{array}{c}40.8(16.8) \\
18-74\end{array}$ & 0.955 & $41.1(18.1)$ & $40.6(15.6)$ & $0.993^{\mathrm{a}}$ \\
\hline $\begin{array}{c}\text { Gender, } \\
\mathrm{M} / \mathrm{F}, n(\%)\end{array}$ & $\begin{array}{c}19 / 35 \\
(35.2 / 64.8)\end{array}$ & $\begin{array}{c}22 / 34 \\
(39.3 / 60.7)\end{array}$ & 0.656 & $\begin{array}{c}14 / 15 \\
(48.3 / 51.7)\end{array}$ & $\begin{array}{c}8 / 19 \\
(29.6 / 70.4)\end{array}$ & $0.320^{\mathrm{a}}$ \\
\hline $\begin{array}{l}\text { Residential area, } \\
\text { rural/urban, } n(\%)\end{array}$ & - & $\begin{array}{c}11 / 45 \\
(19.6 / 80.4)\end{array}$ & & $\begin{array}{c}3 / 26 \\
(10.3 / 89.7)\end{array}$ & $\begin{array}{c}8 / 19 \\
(29.6 / 70.4)\end{array}$ & 0.070 \\
\hline $\begin{array}{c}\text { Education, } \\
\text { university/college/ } \\
\text { secondary school, } n(\%)\end{array}$ & - & $\begin{array}{c}13 / 29 / 14 \\
(23.2 / 51.8 / 25)\end{array}$ & & $\begin{array}{c}7 / 16 / 6 \\
(24.1 / 55.2 / 20.7)\end{array}$ & $\begin{array}{c}6 / 13 / 8 \\
(22.2 / 48.1 / 29.6)\end{array}$ & 0.740 \\
\hline $\begin{array}{c}\text { Marital status, } \\
\text { married/single, } n(\%)\end{array}$ & - & $\begin{array}{c}27 / 29 \\
(48.2 / 51.8) \\
\end{array}$ & & $\begin{array}{c}10 / 19 \\
(34.5 / 65.5)\end{array}$ & $\begin{array}{c}17 / 10 \\
(63.0 / 37.0) \\
\end{array}$ & 0.033 \\
\hline $\begin{array}{l}\text { Having children, } \\
\text { Yes/no, } n(\%)\end{array}$ & - & $\begin{array}{c}31 / 25 \\
(55.4 / 44.6)\end{array}$ & & $\begin{array}{c}14 / 15 \\
(48.3 / 51.7)\end{array}$ & $\begin{array}{c}17 / 10 \\
(63.0 / 37.0)\end{array}$ & 0.269 \\
\hline $\begin{array}{c}\text { Economic status, } \\
\text { low / middle/ high, } n(\%)\end{array}$ & - & $\begin{array}{c}15 / 32 / 9 \\
(26.8 / 57.1 / 16.1) \\
\end{array}$ & & $\begin{array}{c}7 / 17 / 5 \\
(24.1 / 58.6 / 17.2)\end{array}$ & $\begin{array}{c}8 / 15 / 4 \\
(29.6 / 55.6 / 14.8)\end{array}$ & 0.891 \\
\hline $\begin{array}{c}\text { Family history of suicide, } \\
\text { Yes/no, } n(\%)\end{array}$ & - & $\begin{array}{c}8 / 48 \\
(14.3 / 85.7) \\
\end{array}$ & & $\begin{array}{c}2 / 27 \\
(6.9 / 93.1) \\
\end{array}$ & $\begin{array}{c}6 / 21 \\
(22.2 / 77.8)\end{array}$ & 0.104 \\
\hline $\begin{array}{l}\text { Stressful life event one } \\
\text { month before last SA, } \\
\text { Yes/no, } n(\%)\end{array}$ & - & $\begin{array}{c}34 / 22 \\
(60.7 / 39.3)\end{array}$ & & $\begin{array}{c}21 / 8 \\
(72.4 / 27.6 /)\end{array}$ & $\begin{array}{c}13 / 14 \\
(48.1 / 51.9 /)\end{array}$ & 0.063 \\
\hline $\begin{array}{l}\text { Duration of mental disorder, } \\
\text { mean (SD), years }\end{array}$ & - & $3.45(2.41)$ & & $2.38(2.06)$ & $4.59(2.26)$ & $<0.001$ \\
\hline $\begin{array}{l}\text { Previous psychiatric } \\
\text { hospitalization, } \\
\text { Yes/no, } n(\%)\end{array}$ & - & $\begin{array}{c}37 / 19 \\
(66.1 / 33.9)\end{array}$ & & $\begin{array}{c}18 / 11 \\
(62.1 / 37.9)\end{array}$ & $\begin{array}{c}19 / 8 \\
(70.4 / 29.6)\end{array}$ & 0.512 \\
\hline $\begin{array}{c}\text { Period between last } \\
\text { hospitalization and current } \\
\text { SA, mean (SD), years }\end{array}$ & - & $\begin{array}{c}1.0 \\
(0.83)\end{array}$ & & $\begin{array}{c}0.93 \\
(0.84)\end{array}$ & $\begin{array}{c}1.07 \\
(0.83)\end{array}$ & 0.525 \\
\hline $\begin{array}{c}\text { Psychiatric consultation } \\
\text { during lifetime, } \\
\text { Yes } / \text { no, } n(\%)\end{array}$ & - & $\begin{array}{c}48 / 8 \\
(85.7 / 14.3)\end{array}$ & & $\begin{array}{c}21 / 8 \\
(72.4 / 27.6)\end{array}$ & $\begin{array}{c}27 / 0 \\
(100 / 0)\end{array}$ & 0.005 \\
\hline $\begin{array}{c}\text { Psychiatric treatment } 1 \\
\text { month before last SA, } \\
\text { Yes/no }(\%)\end{array}$ & - & $\begin{array}{c}37 / 19 \\
(66.1 / 33.9)\end{array}$ & & $\begin{array}{c}16 / 13 \\
(55.2 / 44.8)\end{array}$ & $\begin{array}{c}21 / 6 \\
(77.8 / 22.2)\end{array}$ & 0.074 \\
\hline $\begin{array}{l}\text { Current psychiatric } \\
\text { diagnosis, } \\
\text { MDD/ other }{ }^{b}, n(\%)\end{array}$ & - & $\begin{array}{c}21 / 35 \\
(37.5 / 62.5)\end{array}$ & & $\begin{array}{c}10 / 19 \\
(34.5 / 65.5)\end{array}$ & $\begin{array}{c}11 / 16 \\
(40.7 / 59.3)\end{array}$ & 0.418 \\
\hline Age at first $S A$, years & - & $38.2(17.2)$ & & $41.1(18.1)$ & $35.1(15.9)$ & 0.201 \\
\hline $\begin{array}{c}\text { History of SA, } \\
\text { First time/repeated, } n(\%)\end{array}$ & - & $\begin{array}{c}29 / 27 \\
(51.8 / 48.2)\end{array}$ & & - & - & \\
\hline $\begin{array}{c}\text { Method of SA, } \\
\text { drugs/physical, } n(\%)\end{array}$ & - & $\begin{array}{c}31 / 25 \\
(55.4 / 44.6)\end{array}$ & & $\begin{array}{c}16 / 13 \\
(55.2 / 44.8)\end{array}$ & $\begin{array}{c}15 / 12 \\
(55.6 / 44.4)\end{array}$ & 0.595 \\
\hline $\begin{array}{c}\text { Alcohol intoxication during } \\
\text { SA, Yes/no, } n(\%)\end{array}$ & - & $\begin{array}{c}22 / 34 \\
(39.3 / 60.7)\end{array}$ & & $\begin{array}{c}12 / 17 \\
(41.4 / 58.6)\end{array}$ & $\begin{array}{c}10 / 17 \\
(37 / 63)\end{array}$ & 0.477 \\
\hline $\begin{array}{c}\text { Smoking, } \\
\text { Yes/no, } n(\%)\end{array}$ & - & $\begin{array}{c}24 / 32 \\
(42.9 / 57.1)\end{array}$ & & $\begin{array}{c}10 / 19 \\
(34.5 / 65.5)\end{array}$ & $\begin{array}{c}14 / 13 \\
(51.9 / 48.1)\end{array}$ & 0.189 \\
\hline $\begin{array}{l}\text { MADRS score, } \\
\text { mean (SD), range }\end{array}$ & - & $\begin{array}{c}16.39(10.43) \\
7-47\end{array}$ & & $\begin{array}{c}16.07(10.02) \\
7-43\end{array}$ & $\begin{array}{l}16.74(11.04) \\
\quad 7-47\end{array}$ & 0.489 \\
\hline
\end{tabular}

HC, healthy controls; SA, suicide attempt; SD, standard deviation; M, male; F, female; MDD, major depressive disorder; MADRS, Montgomery-Asberg depression rating scale; $\mathrm{p}^{\mathrm{a}}$ value between three groups: HC, first SA, SA $>1 .{ }^{\mathrm{b}}$ other diagnoses include: anxiety disorder, borderline personality disorder, adjustment disorder. Significant $p$-value $(p<0.05)$. 


\subsection{MRI Processing and Analysis}

Patients after SA and HC went through the same MRI protocol, which consisted of T2-weighted (T2W)/FLAIR axial (TR 9000ms, TE $89 \mathrm{~ms}$ ) and T2W/fl2d/hemo axial (TR $800 \mathrm{~ms}$, TE26ms) sequences in order to rule out the pathologies as lesions and hemorrhage. Image data were collected using 1.5 Tesla (T) Siemens Avanto (Siemens, Munich, Germany) scanner with a standard quadrature head volume coil. Head movement was prevented by pads inside the coil. Whole-brain T1-weighted (T1W) mpr/p2/iso axial (TR 1900ms, TE $3.35 \mathrm{~ms}, 1 \mathrm{~mm}$ slice thickness) sequence was used for volumetric measurement. During brain MRI, the patients had no suicidal ideation.

All MRI data were subject to strict quality control procedures. First, the radiologists checked T1W images for artefacts. If the latter met the requirements, they were converted to mgz files. Brain cortical thickness and grey- and white-matter volumes were measured using FreeSurfer 6.0 image analysis suite (http:/ / surfer.nmr.mgh.harvard.edu/; accessed on 22 September 2018). This automatic reconstruction technique outweighs standard brain volume measurement due to the fact that it investigates across the whole brain and can locate changes which may be very small or do not match usual anatomical subdivisions. The FreeSurfer software constructs a three-dimensional representation of the cortical surface and volume quantifications applying image intensities and continuity data from the entire MRI volume to create reproductions of the border between gray and white matter and pial surface [4]. FreeSurfer's Desikan-Killiany atlas was used to define regions of interest for the brain cortex: the frontal cortex contained 11 regions, temporal cortex-9 regions $[14,15]$. Freesurfer's automated segmentation of hippocampal substructures divided the hippocampus into 13 subfields [16].

\subsection{Statistical Analysis}

The Shapiro-Wilk test was employed to verify whether the data meet the conditions of the normal distribution. The comparison between all patients after SA and comparison control subjects was performed using two-sample t-tests. Observed differences were considered statistically significant when the calculated significance level ( $p$-value) was lower than the selected significance level $(\alpha=0.05)$. Values for the average cortical thickness were analyzed using a general linear model controlling for the effect of age. ANOVA was used to test the equality of three group means, statistically significant results indicate that not all of the group means are equal. Post hoc tests were used to explore differences between multiple group means. Frontal and TC thickness as well as hippocampus volume was compared among the three groups (control, first SA, SA $>1$ ) using analysis of covariance (ANCOVA), with post hoc pairwise comparisons for age as covariate of interest. The $p$-value was used in the ANOVA output to determine whether the differences between some of the means are statistically significant. $F$ values are based on the pairwise comparisons among the means. $p$-values were adjusted for multiple comparisons using Bonferroni correction for multiple comparisons. An additional entire cortex analysis was performed in order to investigate a potential gender by group interaction in cortical thickness. Covarying for gender in the full-group analyses did affect the results. Thus, the final analyses were performed without covarying for gender. Alpha levels for statistical significance testing were set to 0.05 . IBM SPSS Statistics 23 and Microsoft Excel 2010 were used for statistical analysis.

\section{Results}

All study patients, hospitalized after SA $(n=56)$ were divided into the following two groups: suicide attempters with a history of at least one suicide attempt (first SA group, $n=29$ ), and suicide attempters who reported more than one suicide attempt during the lifetime (SA $>1$ group, $n=27$ ). As reported in Table 1, the groups did not differ significantly in age, gender, main sociodemographic characteristics, psychiatric diagnoses, severity of depressive symptoms or method of suicide attempt, but they did vary in terms of marital status, with a greater proportion of single participants in the first SA group. SA $>1$ group had significantly longer duration of mental disorder $(p<0.001)$ in comparison to the first 
SA group. No differences were found between these groups regarding the psychiatric treatment 1 month before SA and period of time between last hospitalization and current SA. All patients with SA > 1 reported psychiatric consultations during lifetime (more frequently than patients after the first $S A, p=0.005$ ).

The volumetric analysis of all brain structures was done. Overall, significant differences between all SA patients and healthy controls groups were found in frontal and TC thickness and in volume of the left and right parts of hippocampus. Decreased cortical thicknesses were observed in both hemispheres. Analysis of other brain regions did not reveal significant results.

The analysis of frontal cortex thickness is shown in Table 2. The comparison between the patients after first SA and HC revealed the significant lower cortical thickness of the superior frontal $(p=0.041)$ and rostral middle frontal $(p=0.016)$ areas of the left hemisphere and superior frontal area $(p=0.021)$ of the right hemisphere, with relative $3.5,3.58$ and $4.19 \%$ difference of mean cortical thickness in these cortex areas, respectively. Moreover, the comparison between the SA > 1 group and controls revealed the significant lower frontal cortical thickness in ten areas of the left hemisphere and seven areas of the right hemisphere, with relatively higher difference (4.02 to $8.33 \%$ ) of the mean cortical thickness between these two groups. Differences in four of frontal cortex regions were highly significant $(p<0.0001)$ in patients with $\mathrm{SA}>1$ as compared with the control group.

Table 2. The significant differences in means of frontal cortex thickness between the patients after first suicide attempt, repeated suicide attempts and study controls (first $\mathrm{SA}, \mathrm{SA}>1, \mathrm{HC}$ ).

\begin{tabular}{|c|c|c|c|c|c|c|c|c|c|c|}
\hline \multirow[t]{2}{*}{ Hemisphere } & \multirow[t]{2}{*}{$\begin{array}{c}\text { Frontal Cortex } \\
\text { Part }\end{array}$} & \multicolumn{7}{|c|}{ Mean Cortical Thickness $(95 \% \mathrm{CI})$ in $\mathrm{mm}$} & \multicolumn{2}{|c|}{$\begin{array}{c}\text { ANCOVA Age } \\
\text { Adjusted }\end{array}$} \\
\hline & & HC $(n=54)$ & $\begin{array}{c}\text { First SA } \\
(n=29)\end{array}$ & Post-Hoc & $\begin{array}{c}\% \\
\text { Diff. }\end{array}$ & $\begin{array}{l}\mathrm{SA}>1 \\
(n=27)\end{array}$ & Post-Hoc & $\begin{array}{c}\% \\
\text { Diff. }\end{array}$ & & \\
\hline & & 1 & 2 & 1 vs. 2 & $1-2$ & 3 & 1 vs 3 & $1-3$ & $F_{2.106}$ & $p$ \\
\hline \multirow[t]{10}{*}{ Left } & $\begin{array}{c}\text { Lateral } \\
\text { orbitofrontal }\end{array}$ & $\begin{array}{c}2.79 \\
(2.75-2.83)\end{array}$ & $\begin{array}{c}2.72 \\
(2.66-2.77)\end{array}$ & 0.140 & 2.50 & $\begin{array}{c}2.66 \\
(2.60-2.72)\end{array}$ & 0.002 & 4.65 & 6.71 & 0.002 \\
\hline & $\begin{array}{c}\text { Medial } \\
\text { orbitofrontal }\end{array}$ & $\begin{array}{c}2.55 \\
(2.50-2.58)\end{array}$ & $\begin{array}{c}2.54 \\
(2.49-2.60)\end{array}$ & 1.000 & 0.39 & $\begin{array}{c}2.42 \\
(2.36-2.48)\end{array}$ & 0.003 & 5.09 & 6.74 & 0.002 \\
\hline & Pars opercularis & $\begin{array}{c}2.66 \\
(2.61-2.72)\end{array}$ & $\begin{array}{c}2.58 \\
(2.51-2.65)\end{array}$ & 0.149 & 3.00 & $\begin{array}{c}2.48 \\
(2.41-2.55)\end{array}$ & $<0.001$ & 6.77 & 11.29 & $<0.001$ \\
\hline & Pars orbitalis & $\begin{array}{c}2.88 \\
(2.82-2.94)\end{array}$ & $\begin{array}{c}2.78 \\
(2.70-2.86)\end{array}$ & 0.142 & 3.47 & $\begin{array}{c}2.69 \\
(2.61-2.77)\end{array}$ & 0.001 & 6.59 & 7.32 & 0.001 \\
\hline & Pars triangularis & $\begin{array}{c}2.56 \\
(2.51-2.61)\end{array}$ & $\begin{array}{c}2.49 \\
(2.43-2.56)\end{array}$ & 0.329 & 2.73 & $\begin{array}{c}2.41 \\
(2.34-2.48)\end{array}$ & 0.002 & 5.85 & 6.40 & 0.002 \\
\hline & Precentral & $\begin{array}{c}2.52 \\
(2.46-2.56)\end{array}$ & $\begin{array}{c}2.42 \\
(2.35-2.48)\end{array}$ & 0.093 & 3.96 & $\begin{array}{c}2.31 \\
(2.24-2.38)\end{array}$ & $<0.001$ & 8.33 & 10.34 & $<0.001$ \\
\hline & $\begin{array}{l}\text { Rostral middle } \\
\text { frontal }\end{array}$ & $\begin{array}{c}2.51 \\
(2.47-2.54)\end{array}$ & $\begin{array}{c}2.42 \\
(2.37-2.47)\end{array}$ & 0.016 & 3.58 & $\begin{array}{c}2.37 \\
(2.32-2.42)\end{array}$ & $<0.001$ & 5.58 & 11.48 & $<0.001$ \\
\hline & Superior frontal & $\begin{array}{c}2.85 \\
(2.81-2.90)\end{array}$ & $\begin{array}{c}2.75 \\
(2.68-2.81)\end{array}$ & 0.041 & 3.50 & $\begin{array}{c}2.66 \\
(2.59-2.73)\end{array}$ & $<0.001$ & 6.67 & 11.11 & $<0.001$ \\
\hline & Frontal pole & $\begin{array}{c}2.84 \\
(2.76-2.91)\end{array}$ & $\begin{array}{c}2.76 \\
(2.65-2.87)\end{array}$ & 0.765 & 2.81 & $\begin{array}{c}2.66 \\
(2.55-2.77)\end{array}$ & 0.032 & 6.33 & 3.43 & 0.036 \\
\hline & $\begin{array}{l}\text { Caudal middle } \\
\text { frontal }\end{array}$ & $\begin{array}{c}2.64 \\
(2.59-2.69)\end{array}$ & $\begin{array}{c}2.54 \\
(2.48-2.61)\end{array}$ & 0.058 & 3.78 & $\begin{array}{c}2.50 \\
(2.43-2.69)\end{array}$ & 0.002 & 5.3 & 6.78 & 0.002 \\
\hline \multirow[t]{8}{*}{ Right } & $\begin{array}{c}\text { Lateral } \\
\text { orbitofrontal }\end{array}$ & $\begin{array}{c}2.73 \\
(2.68-2.77)\end{array}$ & $\begin{array}{c}2.69 \\
(2.63-2.75)\end{array}$ & 0.944 & 1.46 & $\begin{array}{c}2.62 \\
(2.56-2.68)\end{array}$ & 0.013 & 4.02 & 4.28 & 0.016 \\
\hline & Pars opercularis & $\begin{array}{c}2.63 \\
(2.57-2.68)\end{array}$ & $\begin{array}{c}2.57 \\
(2.49-2.65)\end{array}$ & 0.824 & 2.28 & $\begin{array}{c}2.48 \\
(2.40-2.56)\end{array}$ & 0.011 & 5.70 & 4.39 & 0.015 \\
\hline & Pars orbitalis & $\begin{array}{c}2.86 \\
(2.79-2.91)\end{array}$ & $\begin{array}{c}2.81 \\
(2.72-2.89)\end{array}$ & 1.000 & 1.74 & $\begin{array}{c}2.71 \\
(2.62-2.80)\end{array}$ & 0.026 & 5.24 & 3.58 & 0.031 \\
\hline & Pars triangularis & $\begin{array}{c}2.55 \\
(2.49-2.60)\end{array}$ & $\begin{array}{c}2.51 \\
(2.44-2.58)\end{array}$ & 1.000 & 1.56 & $\begin{array}{c}2.42 \\
(2.35-2.49)\end{array}$ & 0.016 & 5.09 & 4.07 & 0.020 \\
\hline & Precentral & $\begin{array}{c}2.46 \\
(2.41-2.51)\end{array}$ & $\begin{array}{c}2.39 \\
(2.32-2.46)\end{array}$ & 0.290 & 2.84 & $\begin{array}{c}2.31 \\
(2.24-2.38)\end{array}$ & 0.002 & 6.09 & 6.42 & 0.002 \\
\hline & $\begin{array}{l}\text { Rostral middle } \\
\text { frontal }\end{array}$ & $\begin{array}{c}2.46 \\
(2.41-2.50)\end{array}$ & $\begin{array}{c}2.42 \\
(2.36-2.49)\end{array}$ & 1.000 & 1.62 & $\begin{array}{c}2.35 \\
(2.92-2.42)\end{array}$ & 0.040 & 4.47 & 3.19 & 0.045 \\
\hline & Superior Frontal & $\begin{array}{c}2.86 \\
(2.81-2.91)\end{array}$ & $\begin{array}{c}2.74 \\
(2.68-2.81)\end{array}$ & 0.021 & 4.19 & $\begin{array}{c}2.68 \\
(2.62-2.75)\end{array}$ & $<0.001$ & 6.29 & 9.58 & $<0.001$ \\
\hline & $\begin{array}{l}\text { Caudal middle } \\
\text { frontal }\end{array}$ & $\begin{array}{c}2.59 \\
(2.54-2.64)\end{array}$ & $\begin{array}{c}2.51 \\
(2.44-2.58)\end{array}$ & 0.267 & 3.08 & $\begin{array}{c}2.48 \\
(2.40-2.55)\end{array}$ & 0.054 & 4.24 & 3.33 & 0.039 \\
\hline
\end{tabular}

HC, healthy controls; SA, suicide attempt. F, $p$ values are based on the pairwise comparisons among the means (three groups: HC, first SA, SA > 1). \% diff-relative difference describes the difference of the mean cortical thickness between two groups: HC and patients after SA. Significant $p$-values $(p<0.05)$. 
Table 3 presented the comparison of thickness of temporal and frontal cortex among study groups. Patients after first SA, in comparison to HC, had significantly lower cortical thickness of the inferior $(p=0.002)$, middle $(p=0.013)$ and superior $(p=0.006)$ temporal areas of the left hemisphere, with relative $4.09,4.02$ and $4.49 \%$ difference of mean cortical thickness in these cortex areas, respectively. In patients with SA $>1$, in comparison to controls, the significant lower TC thickness was observed in the six areas of both hemispheres, with a difference (3.90 to $6.04 \%$ ) of the mean cortical thickness between these two groups. Differences in the inferior and middle temporal areas of the left hemisphere were observed as highly significant $(p<0.001)$.

Table 3. The significant differences in means of temporal cortex thickness between the patients after first suicide attempt, repeated.

\begin{tabular}{|c|c|c|c|c|c|c|c|c|c|c|}
\hline \multirow[t]{2}{*}{ Hemisphere } & \multirow[t]{2}{*}{$\begin{array}{c}\text { Temporal Cortex } \\
\text { Part }\end{array}$} & \multicolumn{7}{|c|}{ Mean Cortical Thickness $(95 \% \mathrm{CI})$ in $\mathrm{mm}$} & \multicolumn{2}{|c|}{$\begin{array}{c}\text { ANCOVA Age } \\
\text { Adjusted, }\end{array}$} \\
\hline & & $\mathrm{HC}(n=54)$ & $\begin{array}{c}\text { First SA } \\
(n=29)\end{array}$ & Post-Hoc & $\begin{array}{c}\% \\
\text { Diff. }\end{array}$ & $\begin{array}{l}\mathrm{SA}>1 \\
(n=27)\end{array}$ & Post-Hoc & $\begin{array}{c}\% \\
\text { Diff. }\end{array}$ & & \\
\hline & & 1 & 2 & 1 vs. 2 & $1-2$ & 3 & 1 vs 3 & $1-3$ & $F_{2.106}$ & $p$ \\
\hline \multirow[t]{5}{*}{ Left } & Fusiform & $\begin{array}{c}2.78 \\
(2.73-2.83)\end{array}$ & $\begin{array}{c}2.73 \\
(2.66-2.80)\end{array}$ & 0.573 & 1.79 & $\begin{array}{c}2.67 \\
(2.60-2.74)\end{array}$ & 0.031 & 3.90 & 3.53 & 0.033 \\
\hline & Inferior temporal & $\begin{array}{c}2.93 \\
(2.89-2.98)\end{array}$ & $\begin{array}{c}2.81 \\
(2.75-2.87)\end{array}$ & 0.002 & 4.09 & $\begin{array}{c}2.78 \\
(2.72-2.83)\end{array}$ & $<0.001$ & 5.01 & 11.55 & $<0.001$ \\
\hline & Middle temporal & $\begin{array}{c}2.98 \\
(2.93-3.03)\end{array}$ & $\begin{array}{c}2.86 \\
(2.80-2.93)\end{array}$ & 0.013 & 4.02 & $\begin{array}{c}2.80 \\
(2.73-2.86)\end{array}$ & $<0.001$ & 6.04 & 11.29 & $<0.001$ \\
\hline & Superior temporal & $\begin{array}{c}2.89 \\
(2.84-2.93)\end{array}$ & $\begin{array}{c}2.76 \\
(2.70-2.83)\end{array}$ & 0.006 & 4.49 & $\begin{array}{c}2.76 \\
(2.69-2.82)\end{array}$ & 0.005 & 4.49 & 7.61 & 0.001 \\
\hline & Temporal pole & $\begin{array}{c}3.76 \\
(3.67-3.85)\end{array}$ & $\begin{array}{c}3.59 \\
(3.47-3.72)\end{array}$ & 0.100 & 4.52 & $\begin{array}{c}3.54 \\
(3.41-3.66)\end{array}$ & 0.015 & 5.85 & 4.88 & 0.009 \\
\hline Right & Superior temporal & $\begin{array}{c}2.89 \\
(2.84-2.95)\end{array}$ & $\begin{array}{c}2.85 \\
(2.77-2.92)\end{array}$ & 0.995 & 1.38 & $\begin{array}{c}2.77 \\
(2.69-2.85)\end{array}$ & 0.036 & 4.15 & 3.27 & 0.042 \\
\hline
\end{tabular}

HC, healthy controls; SA, suicide attempt. F, $p$ values are based on the pairwise comparisons among the means (three groups: HC, first SA, SA > 1). \% diff-relative difference describes the difference of the mean cortical thickness between two groups: HC and patients after SA. Significant $p$-values $(p<0.05)$.

Significant differences in volume of left and right parts of hippocampus between study controls and all study patients are demonstrated in Table 4.

Table 4. The significant differences in mean volume of hippocampus parts between HC and all study patients.

\begin{tabular}{|c|c|c|c|c|c|c|}
\hline \multirow[t]{2}{*}{ Hemisphere } & \multirow[t]{2}{*}{$\begin{array}{c}\text { Part of } \\
\text { Hippocampus }\end{array}$} & \multicolumn{3}{|c|}{ Mean Volume $(95 \% \mathrm{CI})$ in $\mathrm{mm}^{3}$} & \multicolumn{2}{|c|}{$\begin{array}{c}\text { ANCOVA } \\
\text { Age Adjusted }\end{array}$} \\
\hline & & HC $(n=54)$ & $\begin{array}{l}\text { All Patients after SA } \\
\qquad(n=56)\end{array}$ & $\%$ Diff & & \\
\hline & & 1 & 2 & $1-2$ & $F_{1.107}$ & $p$ \\
\hline \multicolumn{7}{|l|}{ Left } \\
\hline & ML & $564.42(545.31-583.55)$ & $536.10(517.28-554.93)$ & 5.01 & 2.97 & 0.039 \\
\hline & GC-DG & $292.54(282.38-302.68)$ & $273.57(263.63-283.52)$ & 6.48 & 3.79 & 0.009 \\
\hline & CA3 & 195.78 (188.04-203.51) & $183.84(176.24-191.43)$ & 6.09 & 4.77 & 0.031 \\
\hline & CA4 & $250.55(241.90-259.22)$ & $236.85(228.38-245.32)$ & 5.46 & 5.05 & 0.027 \\
\hline & HATA & $58.31(55.76-60.87)$ & $52.94(50.44-55.44)$ & 9.20 & 4.46 & 0.004 \\
\hline \multicolumn{7}{|l|}{ Right } \\
\hline & Subiculum & $428.21(411.15-445.27)$ & $404 . .3(387.15-420.91)$ & 5.58 & 3.35 & 0.049 \\
\hline & CA1 & $640.27(616.07-664.45)$ & $605.72(581.90-629.54)$ & 5.39 & 4.06 & 0.047 \\
\hline & ML & $574.35(553.83-594.88)$ & $545.01(524.75-565.26)$ & 5.10 & 3.09 & 0.047 \\
\hline & GC-DG & $303.14(292.17-314.10)$ & $287.19(276.44-297.94)$ & 5.26 & 4.25 & 0.042 \\
\hline & HATA & $61.01(58.18-63.84)$ & $56.54(53.76-59.31)$ & 7.32 & 5.02 & 0.027 \\
\hline
\end{tabular}

HC, healthy controls; SA, suicide attempt; ML, molecular layer; GC-DG, granule cell layer of dentate gyrus; CA, cornu amonis; HATA, hippocampus-amygdala transition area. F, $p$-values are based on the pairwise comparisons among the means (two groups: HC and all patients after SA). \% diff-relative difference describes the difference of the mean hippocampus volume between two study groups: HC and patients after SA. Significant $p$-values $(p<0.05)$ are indicated in bold.

Analysis of patients with history of first SA did not reveal significant differences in volume of hippocampus parts, in comparison to HC (Table 5). However, the comparison of 
controls to patients with SA > 1 reported significant differences in mean volume of left and right parts of hippocampus volume, with 7.86 to $9.89 \%$ relative differences of the mean hippocampus volume between two groups.

Table 5. The significant differences in hippocampus part mean volume between the patients after first suicide attempt, repeated suicide attempts and study controls (first SA, SA > 1 and $\mathrm{HC}$ ).

\begin{tabular}{|c|c|c|c|c|c|c|c|c|c|c|}
\hline \multirow[t]{2}{*}{ Hemisphere } & \multirow[t]{2}{*}{$\begin{array}{c}\text { Part of } \\
\text { Hippocampus }\end{array}$} & \multicolumn{7}{|c|}{ Mean Volume $(95 \% \mathrm{CI})$ in $\mathrm{mm}^{3}$} & \multicolumn{2}{|c|}{$\begin{array}{c}\text { ANOVA Age } \\
\text { Adjusted }\end{array}$} \\
\hline & & HC $(n=54)$ & $\begin{array}{c}\text { First SA } \\
(n=29)\end{array}$ & Post-Hoc & $\begin{array}{c}\% \\
\text { Diff. }\end{array}$ & $\begin{array}{c}\text { SA > 1 } \\
(n=27)\end{array}$ & Post-Hoc & $\begin{array}{c}\% \\
\text { Diff. }\end{array}$ & & \\
\hline & & 1 & 2 & 1 vs. 2 & $1-2$ & 3 & 1 vs. 3 & $1-3$ & $F_{2.106}$ & $p$ \\
\hline \multicolumn{11}{|c|}{ - } \\
\hline & GC-DG & $\begin{array}{c}292.54 \\
(282.38-302.68)\end{array}$ & $\begin{array}{c}277.34 \\
(263.49-291.19)\end{array}$ & 0.247 & 5.19 & $\begin{array}{c}269.52 \\
(255.17-283.88)\end{array}$ & 0.032 & 7.86 & 3.79 & 0.026 \\
\hline & HATA & $\begin{array}{l}58.31 \\
(55.76-60.87)\end{array}$ & $\begin{array}{c}53.32 \\
(49.83-56.81)\end{array}$ & 0.072 & 8.56 & $\begin{array}{c}52.54 \\
(48.92-56.15)\end{array}$ & 0.033 & 9.89 & 4.46 & 0.014 \\
\hline \multicolumn{11}{|c|}{ (20001 } \\
\hline & Subiculum & $\begin{array}{c}428.21 \\
(411.15-445.27)\end{array}$ & $\begin{array}{c}417.39 \\
(394.12-440.67)\end{array}$ & 1.000 & 2.52 & $\begin{array}{c}389.67 \\
(365.54-413.80)\end{array}$ & 0.043 & 9.00 & 3.35 & 0.039 \\
\hline
\end{tabular}

HC, healthy controls; SA, suicide attempt; GC-DG, granule cell layer of dentate gyrus; HATA, hippocampus-amygdala-transition-area. F, $p$-values are based on the pairwise comparisons among the means (three groups: HC, first SA, SA $>1$ ). \% diff-relative difference describes the difference of the mean hippocampus volume between two groups. Significant $p$-values $(p<0.05)$ are indicated in bold.

Post-hoc analyses revealed no significant within group differences in brain thickness and hippocampus parts volume in the groups of patients after SA, when comparing first SA group $(n=29)$ to SA $>1$ group $(n=27)$.

The comparison of frontal and temporal cortex thickness and the volumes of hippocampus parts of all study patients with history of SA according to psychiatric diagnoses (major depressive disorder vs. other diagnosis), method of suicidal attempt (intoxication with drugs vs. physical suicidal act) and acute alcohol intoxication before SA (yes vs. no) did not reveal significant differences.

\section{Discussion}

To our knowledge, it is the first study, which compared volumetric brain parameters in acute suicidal patients after first and repeated suicidal attempts to healthy subjects without a history of suicidal attempt and mental disorder. The main finding of this research was that already after the first suicide attempt in comparison to healthy controls lower cortical thickness was observed in temporal and frontal areas; smaller size of some parts of hippocampus structure was found in suicidal patients.

According to the data of literature, about $90 \%$ of suicide attempters usually had some kind of untreated psychological disorder, $50-70 \%$ of the time that disorder was depression $[17,18]$. In our study as many as a third of the patients had MDD, but more than half had records of psychiatric hospitalization and previous psychiatric treatment. Women, as a group, demonstrated more attempts, which can be explained by a weaker intention to die, but a stronger desire to communicate distress [19]. However, the majority of patients did not had records of suicide in family which was linked to self-harm in other studies by genetic transfer $[20,21]$. On the other hand, more than half of subjects were diagnosed with adjustment disorder and experienced a recent stressful life event, which is a risk factor for suicidal behaviors, as it frequently precedes a suicide attempt [22]. Our study showed that married people were more likely to repeat a suicide attempt. It suggests that if a person feels emotionally unsupported being married or living in a couple, relationship status could not serve as a protective factor for suicidal behaviors. This supports other authors data that multiple suicide attempters tend to be single [23] and have middle economic status [24]. Other studies state that low income contributes to more SA, this question is debatable and relies more on country economic status $[25,26]$. It was found that more SA lived in urbanized area, as in study of Qin et all (2003), but contradicts to Turecki et all (2016), which stated that rural areas are associated with three times the risk of suicide [24,27]. 
Volumetric brain analysis in our study revealed that frontal cortex thickness was reduced in rostral middle frontal region on the left hemisphere and superior frontal regions in both hemispheres. Moreover, these differences in cortical thickness were significantly higher in the assessment of patients after repeated suicide attempts: the significant difference in cortical thinning of almost all frontal regions was found.

Many studies investigated frontal cortex role in suicidality. It is known that DL, VL areas of PFC and ACC regulate behaviour and emotions [28]. The aforementioned changes lead to impaired behavioural control and impulsive behaviour. It is thought that in an emotionally unstable person the frontal cortex limbic system inhibition is not sufficient enough, which causes impulsive, irrational decision making and emotional liability in individuals [29-31]. In the findings of other researchers, cortex thinning in PFC and OFC areas was linked with suicidality [32,33]. Atrophy in prefrontal cortex ventrolateral, dorsolateral and anterior cingulate parts was also discovered in MDD, bipolar depression and schizophrenia patients who attempted suicide $[5,6,34]$. Study of Wang et al. found that MDD patients with a history of SA had a reduced volume in the right and left amygdala and ventral, medial, dorsal PFC. These demonstrate the role of the amygdala and PFC in the pathogenesis of suicidal behavior and imply the amygdala-PFC circuit as a probable target for detection and prevention of suicidal behaviors [35].

Our study has also revealed significant differences in superior frontal gyrus, rostral middle frontal gyrus, pars triangularis and precentral gyrus and other areas of frontal cortex. It has been investigated that pars triangularis is associated with cognitive control of memory and may contribute to suicidal behaviors through a connection with hippocampus [36]. The prefrontal cortex is also linked to suicidality because of its role in executive functions [37]. Other frontal cortex regions involved in suicide have not yet been investigated.

Furthermore, our investigation of temporal lobe structures revealed reduced cortical thickness in inferior, middle and superior regions in patients with first suicidal attempt and nearly all TC regions - in patients with repeated suicidal attempts. It is known about the association of TC with limbic structures and the PFC: these interfaces are important in recognizing and controlling mood and emotion [38]. Superior temporal gyrus is related to emotional intelligence, the ability of following own and others' emotions to make decisions and perform actions [6]. Superior temporal gyrus and sulcus are the components of the face recognition system [39]. This gyrus becomes active upon seeing scared faces [40]. Superior temporal sulcus, amygdala and insula analyse movements of other objects, providing information about their intentions [41]. In addition, these structures regulate a sudden, reflexive response to negative visual stimuli [42]. In other studies, the role of TC in suicidality has been mainly linked to degradation in medial and superior cortices $[6,33,40,43,44]$. This could be due to the fact that temporal lobe contributes to emotion responding [45]. Our research has demonstrated significant volumetric results in the previously mentioned middle, superior TC and also in inferior, left fusiform and left temporal pole. Similar findings were reported in other studies that investigated fusiform relation to borderline personality disorder, while smaller temporal pole is associated with psychotic disorders and suicide attempts $[40,46]$.

One of the aims of our study was to examine hippocampus structure differences in patients who attempted suicide. This structure is known to be associated with the pathophysiology of mental disorders, while the main function of the hippocampus is memory processing. Changes in this cognitive function were associated with suicidal behaviors and lower hippocampal volume in individuals who attempted suicide [47]. As expected, our study demonstrated that suicide attempters showed significant volume differences in some left and right parts of hippocampus structures. However, some hippocampus regions were found as reduced only in patients after repeated SA, without significant differences in patients after first suicidal attempt in comparison to controls. Our findings supported the Colle et al. study in which depressed suicide patients had smaller right and total hippocampus volume than non-suicidal attempters. Hippocampal volumes were negatively associated with impulsivity in individuals; high lethality attempts were associated 
with smaller volumes of the hippocampus and parahippocampal gyrus in adult suicidal attempters [40,48]. Other study of Gosnell and colleagues found smaller hippocampus in depressed suicidal patients in comparison to healthy controls. However, they did not find differences in hippocampus of suicidal and not suicidal depressive patients. Researchers hypothesized that hippocampus volume differences could be due to a characteristic other than suicidality [32]. Sapolsky's theory is based on stress model-hippocampus could be damaged by stress-induced release of steroidal and inflammatory substances [49]. It has been also found that hippocampus modulates the activity of the hypothalamic-pituitaryadrenal axis which is impaired in people who have attempted suicide, not to mention the prefrontal cortex which performed executing functions and is regulated by the hippocampus [50,51]. As mentioned before, the majority of suicide patients in this study experienced a stressful life event one month before SA or were diagnosed with adjustment disorder. We believe that stress might be a risk factor for the atrophy of hippocampus and it could lead to suicidal behaviors. This lends support to previous findings in the literature suggesting that acute stressing event and high levels of cortisol could associate with decreased volume of the hippocampus [52].

A growing body of literature has discovered that mental disorders, especially MDD and schizophrenia, are related to suicidal behaviors [18,53]; affective disorders comprise more than half of all suicide deaths [54]. In our study, only one-third of patients were diagnosed with MDD, other patients had adjustment disorder, anxiety disorders and personality disorders. However, our study results revealed that reduced brain volume in suicidal patients was completely unrelated to neither age, gender, method of suicide attempt or diagnosis of MDD. Most of the volumetric studies evaluating suicidal patients provided observations when comparing suicidal vs. non-suicidal patients with an affective or psychotic disorder. Hippocampus volume reduction was one of the most frequently reported finding, associated with MDD, however changes in size of hippocampus remain unclear in suicide attempters without known mental or neurological disorder [55-57]. Smaller hippocampus in patients with MDD was related to the levels of serum brainderived neurotrophic factor (BDNF) and it may be a significant underlying factor in hippocampal volume differences between patients with MDD and healthy subjects [58]. On the contrary, other authors emphasized that the diagnosis of MDD was not significantly related to hippocampal volume. Our study did not reveal any significant hippocampal volume differences between suicide attempters with and without MDD and our results let us to emphasize that suicidal behaviors but not on MDD may influence the changes in size of hippocampus [59].

Frodl et al. stated that reduction of hippocampus in patients with MDD cannot be confirmed during the three-year follow-up period, but he underlined that atrophy of hippocampus may contribute to the development of MDD and poor clinical outcome in patients [59]. Hippocampus volume changes in suicidal behaviours remained contradictory [60]. Hence, at this stage of understanding, we hypothesized that the model of suicidal behaviours is related to the reduction of brain volume in specific brain regions-frontal, temporal cortex and hippocampal structures. Moreover, these changes become express with repeated suicidal attempts.

This study has some limitations. The first is a cross-sectional study design. This bears importance because differentiating the cause and effect becomes impossible-we are unable to tell whether reduced brain volume contributes to suicidal behaviours or the opposite. The second is that we were unable to compare brain volumetric data in patients with mental disorders without a history of prior suicide attempt. The large sample was useful for exploring hippocampus changes after first suicidal attempt. The prospective analysis of structural brain changes after each repeated SA could provide more clear information about neuroimaging markers of the suicidal brain. 


\section{Conclusions}

We concluded that acute hospitalized suicide attempters had lower cortical thickness in frontal and temporal brain regions of and smaller parts of hippocampus than healthy subjects, without history of suicide attempt and mental disorder. These differences were found independently to patients' age, gender or diagnosis of depressive disorder. The atrophy of frontal, temporal cortex and hippocampus parts was significantly higher in repeated suicide attempters than in first suicide attempters. These findings suggest that repeated suicidal behaviors are associated with intensifying changes in specific brain structures.

Author Contributions: V.S., R.G. and V.A. designed the study and wrote the protocol. V.S. and K.D. coordinated the study, performed the selection of the subjects and psychiatric evaluation, collected and analyzed the data. R.G. organized MRI brain scans and analyzed the data. M.S. performed volumetric brain analysis using FreeSurfer. V.S., M.S. and N.R. analyzed the data and performed the statistical analysis. M.S. and V.S. wrote the first draft of the manuscript. All authors have read and agreed to the published version of the manuscript.

Funding: This research received no external funding.

Institutional Review Board Statement: The study was conducted according to the guidelines of the Declaration of Helsinki, and approved by the Kaunas Regional Biomedical Research Ethics Committee of LITHUANIAN UNIVERITY OF HEALTH SCIENCES (BEC-LSMUCR-67; 2017-06-23).

Informed Consent Statement: Informed consent was obtained from all subjects involved in the study.

Data Availability Statement: The data presented in this study are available on request from the corresponding author. The data are not publicly available due to ethical restrictions.

Acknowledgments: The authors wish to thank all patients and control subjects for participating in the study, as well as, radiology technicians from the radiology department for performing MRI scans.

Conflicts of Interest: The authors declare no conflict of interest.

\section{References}

1. WHO. Global Health Observatory (GHO) data. In Suicide Rates (Per 100,000 Population); WHO: Geneva, Switzerland, 2018.

2. European Commission. Eurostat database. In State of Health in the EU Lithuania Country Health Profile; European Commission: Luxembourg, 2017.

3. Ludwig, B.; Roy, B.; Wang, Q.; Birur, B.; Dwivedi, Y. The Life Span Model of Suicide and Its Neurobiological Foundation. Front. Neurosci. 2017, 11, 74. [CrossRef]

4. Domínguez-Baleón, C.; Gutiérrez-Mondragón, L.F.; Campos-González, A.I.; Rentería, M.E. Neuroimaging Studies of Suicidal Behavior and Non-suicidal Self-Injury in Psychiatric Patients: A Systematic Review. Front. Psychiatry 2018, 9, 500. [CrossRef]

5. Wagner, G.; Schultz, C.C.; Koch, K.; Schachtzabel, C.; Sauer, H.; Schlösser, R.G. Prefrontal cortical thickness in depressed patients with high-risk for suicidal behavior. J. Psychiatr. Res. 2012, 46, 1449-1455. [CrossRef]

6. Aguilar, E.; García-Martí, G.; Martí-Bonmatí, L.; Lull, J.; Moratal, D.; Escartí, M.; Robles, M.; González, J.; Guillamón, M.; Sanjuán, J. Left orbitofrontal and superior temporal gyrus structural changes associated to suicidal behavior in patients with schizophrenia. Prog. Neuro-Psychopharmacol. Biol. Psychiatry 2008, 32, 1673-1676. [CrossRef]

7. Rüsch, N.; Spoletini, I.; Wilke, M.; Martinotti, G.; Bria, P.; Trequattrini, A.; Bonaviri, G.; Caltagirone, C.; Spalletta, G. Inferior frontal white matter volume and suicidality in schizophrenia. Psychiatry Res. Neuroimaging 2008, 164, 206-214. [CrossRef]

8. Spoletini, I.; Piras, F.; Fagioli, S.; Rubino, I.A.; Martinotti, G.; Siracusano, A.; Caltagirone, C.; Spalletta, G. Suicidal attempts and increased right amygdala volume in schizophrenia. Schizophr. Res. 2011, 125, 30-40. [CrossRef]

9. Jovev, M.; Garner, B.; Phillips, L.; Velakoulis, D.; Wood, S.J.; Jackson, H.J.; Pantelis, C.; McGorry, P.D.; Chanen, A.M. An MRI study of pituitary volume and parasuicidal behavior in teenagers with first-presentation borderline personality disorder. Psychiatry Res. Neuroimaging 2008, 162, 273-277. [CrossRef] [PubMed]

10. Monkul, E.S.; Hatch, J.P.; Nicoletti, M.A.; Spence, S.; Brambilla, P.; De Lacerda, A.L.T.; Sassi, R.B.; Mallinger, A.G.; Keshavan, M.S.; Soares, J.C. Fronto-limbic brain structures in suicidal and non-suicidal female patients with major depressive disorder. Mol. Psychiatry 2006, 12, 360-366. [CrossRef] [PubMed]

11. American Psychiatric Association. Diagnostic and Statistical Manual of Mental Disorders (DSM-5 (R.)); Psychiatric Association Publishing: Arlington, VA, USA, 2013.

12. Williams, J.B.W.; Kobak, K.A. Development and reliability of a structured interview guide for the Montgomery-Åsberg Depression Rating Scale (SIGMA). Br. J. Psychiatry 2008, 192, 52-58. [CrossRef] [PubMed] 
13. Crosby, A.; Ortega, L.; Melanson, C. Self-Directed Violence Surveillance: Uniform Definitions and Recommended Data Elements; Centers for Disease Control and Prevention, National Center for Injury Prevention and Control: Atlanta, GA, USA, 2011.

14. Dale, A.M.; Fischla, B.; Sereno, M.I. Cortical Surface-Based Analysis. NeuroImage 1999, 9, 179-194. [CrossRef] [PubMed]

15. Desikan, R.S.; Ségonne, F.; Fischl, B.; Quinn, B.T.; Dickerson, B.C.; Blacker, D.; Buckner, R.L.; Dale, A.M.; Maguire, R.P.; Hyman, B.T.; et al. An automated labeling system for subdividing the human cerebral cortex on MRI scans into gyral based regions of interest. NeuroImage 2006, 31, 968-980. [CrossRef]

16. Iglesias, J.E.; Van Leemput, K.; Augustinack, J.; Insausti, R.; Fischl, B.; Reuter, M. Bayesian longitudinal segmentation of hippocampal substructures in brain MRI using subject-specific atlases. NeuroImage 2016, 141, 542-555. [CrossRef] [PubMed]

17. Hawton, K.; Saunders, K.E.; O'Connor, R.C. Self-harm and suicide in adolescents. Lancet 2012, 379, 2373-2382. [CrossRef]

18. Qin, P. The impact of psychiatric illness on suicide: Differences by diagnosis of disorders and by sex and age of subjects. $J$. Psychiatr. Res. 2011, 45, 1445-1452. [CrossRef] [PubMed]

19. Freeman, A.; Mergl, R.; Kohls, E.; Székely, A.; Gusmao, R.; Arensman, E.; Koburger, N.; Hegerl, U.; Rummel-Kluge, C. A cross-national study on gender differences in suicide intent. BMC Psychiatry 2017, 17, 1-11. [CrossRef] [PubMed]

20. Brent, D.A.; Mann, J.J. Family genetic studies, suicide, and suicidal behavior. Am. J. Med. Genet. Part C Semin. Med. Genet. 2005, 133, 13-24. [CrossRef] [PubMed]

21. Van Heeringen, K. Stress-diathesis model of suicidal behavior. In The Neurobiological Basis of Suicide; CRC Press: Boca Raton, FL, USA, 2012; pp. 113-123. Available online: https:/ / www.ncbi.nlm.nih.gov/books/NBK107203/ (accessed on 29 September 2019).

22. Wang, Y.; Sareen, J.; Afifi, T.O.; Bolton, S.-L.; Johnson, E.A.; Bolton, J.M. Recent Stressful Life Events and Suicide Attempt. Psychiatr. Ann. 2012, 42, 101-108. [CrossRef]

23. Michaelis, B.H.; Goldberg, J.F.; Singer, T.M.; Garno, J.L.; Ernst, C.L.; Davis, G.P. Characteristics of first suicide attempts in single versus multiple suicide attempters with bipolar disorder. Compr. Psychiatry 2003, 44, 15-20. [CrossRef]

24. Qin, P.; Agerbo, E.; Mortensen, P.B. Suicide Risk in Relation to Socioeconomic, Demographic, Psychiatric, and Familial Factors: A National Register-Based Study of All Suicides in Denmark, 1981-1997. Am. J. Psychiatry 2003, 160, 765-772. [CrossRef]

25. Iemmi, V.; Bantjes, J.; Coast, E.; Channer, K.; Leone, T.; McDaid, D.; Palfreyman, A.; Stephens, B.; Lund, C. Suicide and poverty in low-income and middle-income countries: A systematic review. Lancet Psychiatry 2016, 3, 774-783. [CrossRef]

26. Nock, M.K.; Borges, G.; Bromet, E.J.; Alonso, J.; Angermeyer, M.; Beautrais, A.; Bruffaerts, R.; Chiu, W.T.; De Girolamo, G.; Gluzman, S.; et al. Cross-national prevalence and risk factors for suicidal ideation, plans and attempts. Br. J. Psychiatry 2008, 192, 98-105. [CrossRef]

27. Turecki, G.; A Brent, D. Suicide and suicidal behaviour. Lancet 2016, 387, 1227-1239. [CrossRef]

28. McCarthy, C.S.; Eramprashad, A.; Ethompson, C.; Ebotti, J.-A.; Coman, I.L.; Kates, W.R. A comparison of FreeSurfer-generated data with and without manual intervention. Front. Neurosci. 2015, 9, 379. [CrossRef]

29. Sanfilipo, M.; LaFargue, T.; Rusinek, H.; Arena, L.; Loneragan, C.; Lautin, A.; Feiner, D.; Rotrosen, J.; Wolkin, A. Volumetric Measure of the Frontal and Temporal Lobe Regions in Schizophrenia. Arch. Gen. Psychiatry 2000, 57, 471-480. [CrossRef]

30. Shamay-Tsoory, S.G.; Harari, H.; Aharon-Peretz, J.; Levkovitz, Y. The role of the orbitofrontal cortex in affective theory of mind deficits in criminal offenders with psychopathic tendencies. Cortex 2010, 46, 668-677. [CrossRef] [PubMed]

31. Joiner, T.E.; Brown, J.S.; Wingate, L.R. The Psychology and Neurobiology of Suicidal Behavior. Annu. Rev. Psychol. 2005, 56, 287-314. [CrossRef] [PubMed]

32. Gosnell, S.N.; Velasquez, K.M.; Molfese, D.L.; Molfese, P.J.; Madan, A.; Fowler, J.C.; Frueh, B.C.; Baldwin, P.R.; Salas, R. Prefrontal cortex, temporal cortex, and hippocampus volume are affected in suicidal psychiatric patients. Psychiatry Res. Neuroimaging 2016, 256, 50-56. [CrossRef]

33. Giakoumatos, C.I.; Tandon, N.; Shah, J.; Mathew, I.T.; Brady, R.O.; Clementz, B.A.; Pearlson, G.D.; Thaker, G.K.; Tamminga, C.A.; Sweeney, J.A.; et al. Are structural brain abnormalities associated with suicidal behavior in patients with psychotic disorders? J. Psychiatr. Res. 2013, 47, 1389-1395. [CrossRef] [PubMed]

34. Ding, Y.; Lawrence, N.S.; Olié, E.; Cyprien, F.; Le Bars, E.; Bonafé, A.; Phillips, M.L.; Courtet, P.; Jollant, F. Prefrontal cortex markers of suicidal vulnerability in mood disorders: A model-based structural neuroimaging study with a translational perspective. Transl. Psychiatry 2015, 5, e516. [CrossRef] [PubMed]

35. Wang, L.; Zhao, Y.; Edmiston, E.K.; Womer, F.Y.; Zhang, R.; Zhao, P.; Jiang, X.; Wu, F.; Kong, L.; Zhou, Y.; et al. Structural and Functional Abnormities of Amygdala and Prefrontal Cortex in Major Depressive Disorder with Suicide Attempts. Front. Psychiatry 2020, 10, 923. [CrossRef]

36. Badre, D.; Wagner, A.D. Left ventrolateral prefrontal cortex and the cognitive control of memory. Neuropsychology 2007, 45, 2883-2901. [CrossRef] [PubMed]

37. Fuster, J.M.; Bressler, S.L. Past Makes Future: Role of pFC in Prediction. J. Cogn. Neurosci. 2015, 27, 639-654. [CrossRef]

38. Lindquist, K.A.; Wager, T.D.; Kober, H.; Bliss-Moreau, E.; Barrett, L.F. The brain basis of emotion: A meta-analytic review. Behav. Brain Sci. 2012, 35, 121-143. [CrossRef]

39. Takeuchi, H.; Taki, Y.; Sassa, Y.; Hashizume, H.; Sekiguchi, A.; Fukushima, A.; Kawashima, R. Regional gray matter density associated with emotional intelligence: Evidence from voxel-based morphometry. Hum. Brain Mapp. 2010, 32, 1497-1510. [CrossRef] [PubMed]

40. Soloff, P.H.; Pruitt, P.; Sharma, M.; Radwan, J.; White, R.; Diwadkar, V.A. Structural brain abnormalities and suicidal behavior in borderline personality disorder. J. Psychiatr. Res. 2012, 46, 516-525. [CrossRef] 
41. Radua, J.; Phillips, M.L.; Russell, T.; Lawrence, N.; Marshall, N.; Kalidindi, S.; El-Hage, W.; McDonald, C.; Giampietro, V.; Brammer, M.J.; et al. Neural response to specific components of fearful faces in healthy and schizophrenic adults. NeuroImage 2010, 49, 939-946. [CrossRef] [PubMed]

42. Allison, T.; Puce, A.; McCarthy, G. Social perception from visual cues: Role of the STS region. Trends Cogn. Sci. 2000, 4 , 267-278. [CrossRef]

43. Benedetti, F.; Radaelli, D.; Poletti, S.; Locatelli, C.; Falini, A.; Colombo, C.; Smeraldi, E. Opposite effects of suicidality and lithium on gray matter volumes in bipolar depression. J. Affect. Disord. 2011, 135, 139-147. [CrossRef]

44. Pan, L.A.; Ramos, L.; Segreti, A.; Brent, D.A.; Phillips, M.L. Right superior temporal gyrus volume in adolescents with a history of suicide attempt. Br. J. Psychiatry 2015, 206, 339-340. [CrossRef] [PubMed]

45. Buhle, J.T.; Silvers, J.A.; Wager, T.D.; Lopez, R.; Onyemekwu, C.; Kober, H.; Weber, J.; Ochsner, K.N. Cognitive Reappraisal of Emotion: A Meta-Analysis of Human Neuroimaging Studies. Cereb. Cortex 2014, 24, 2981-2990. [CrossRef]

46. Harenski, C.L.; Brook, M.; Kosson, D.S.; Bustillo, J.R.; Harenski, K.A.; Caldwell, M.F.; Van Rybroek, G.J.; Koenigs, M.; Decety, J.; Thornton, D.M.; et al. Socio-neuro risk factors for suicidal behavior in criminal offenders with psychotic disorders. Soc. Cogn. Affect. Neurosci. 2017, 12, 70-80. [CrossRef]

47. Richard-Devantoy, S.; Berlim, M.T.; Jollant, F. A meta-analysis of neuropsychological markers of vulnerability to suicidal behavior in mood disorders. Psychol. Med. 2013, 44, 1663-1673. [CrossRef]

48. Soloff, P.; White, R.; Diwadkar, V.A. Impulsivity, aggression and brain structure in high and low lethality suicide attempters with borderline personality disorder. Psychiatry Res. Neuroimaging 2014, 222, 131-139. [CrossRef] [PubMed]

49. Sapolsky, R.M. Glucocorticoids and Hippocampal Atrophy in Neuropsychiatric Disorders. Arch. Gen. Psychiatry 2000, 57, 925-935. [CrossRef] [PubMed]

50. Mann, J.J.; Currier, D.; Stanley, B.; Oquendo, M.A.; Amsel, L.V.; Ellis, S.P. Can biological tests assist prediction of suicide in mood disorders? Int. J. Neuropsychopharmacol. 2005, 9, 465-474. [CrossRef]

51. Jollant, F.; Lawrence, N.L.; Olié, E.; Guillaume, S.; Courtet, P. The suicidal mind and brain: A review of neuropsychological and neuroimaging studies. World J. Biol. Psychiatry 2011, 12, 319-339. [CrossRef]

52. Moica, T.; Grecu, I.G.; Moica, S.; Grecu, M.G.; Buicu, G.E. Cortisol and Hippocampal Volume as Predictors of Active Suicidal Behavior in Major Depressive Disorder: Case Report. Balk. Med. J. 2016, 33, 706-709. [CrossRef] [PubMed]

53. Bachmann, S. Epidemiology of Suicide and the Psychiatric Perspective. Int. J. Environ. Res. Public Health 2018, 15, 1425. [CrossRef] [PubMed]

54. Chesney, E.; Goodwin, G.M.; Fazel, S. Risks of all-cause and suicide mortality in mental disorders: A meta-review. World Psychiatry 2014, 13, 153-160. [CrossRef] [PubMed]

55. Wise, T.; Radua, J.; Via, E.; Cardoner, N.; Abe, O.; Adams, T.M.; Amico, F.; Cheng, Y.; Cole, J.H.; Périco, C.D.A.M.; et al. Common and distinct patterns of grey-matter volume alteration in major depression and bipolar disorder: Evidence from voxel-based meta-analysis. Mol. Psychiatry 2017, 22, 1455-1463. [CrossRef]

56. Zhao, Y.-J.; Du, M.-Y.; Huang, X.-Q.; Lui, S.; Chen, Z.-Q.; Liu, J.; Luo, Y.; Wang, X.-L.; Kemp, G.J.; Gong, Q.-Y. Brain grey matter abnormalities in medication-free patients with major depressive disorder: A meta-analysis. Psychol. Med. 2014, 44, 2927-2937. [CrossRef] [PubMed]

57. Santos, M.A.O.; Bezerra, L.S.; Carvalho, A.R.M.R.; Brainer-Lima, A.M. Global hippocampal atrophy in major depressive disorder: A meta-analysis of magnetic resonance imaging studies. Trends Psychiatry Psychother. 2018, 40, 369-378. [CrossRef] [PubMed]

58. Eker, C.; Kitis, O.; Taneli, F.; Eker, O.D.; Ozan, E.; Yucel, K.; Coburn, K.; Gonul, A.S. Correlation of serum BDNF levels with hippocampal volumes in first episode, medication-free depressed patients. Eur. Arch. Psychiatry Clin. Neurosci. 2010, 260, 527-533. [CrossRef]

59. Frodl, T.; Jäger, M.; Smajstrlova, I.; Born, C.; Bottlender, R.; Palladino, T. Effect of hippocampal and amygdala volumes on clin-ical outcomes in major depression: A 3-year prospective magnetic resonance imaging study. J. Psychiatry Neurosci. 2008, 33, 423-430. [PubMed]

60. Chen, F.; Bertelsen, A.B.; Holm, I.E.; Nyengaard, J.R.; Rosenberg, R.; Dorph-Petersen, K.-A. Hippocampal volume and cell number in depression, schizophrenia, and suicide subjects. Brain Res. 2020, 1727, 146546. [CrossRef] [PubMed] 